1 Fundação Oswaldo Cruz (Fiocruz), Escola Nacional de Saúde Pública Sergio Arouca (Ensp) - Rio de Janeiro (RJ), Brasil. analupontes64@gmail.com

2 Universidade Federal do Rio de Janeiro, Museu Nacional - Rio de Janeiro (RJ), Brasil.

${ }^{3}$ Fundação Oswaldo Cruz (Fiocruz), Casa de Oswaldo Cruz (COC) - Rio de Janeiro (RJ), Brasil.

\section{Diálogos entre indigenismo e Reforma Sanitária: bases discursivas da criação do subsistema de saúde indígena}

\author{
Dialogues between indigenism and Health Reform: discursive bases of \\ the creation of the indigenous health subsystem
}

Ana Lucia de Moura Pontes ${ }^{\mathbf{1}}$, Felipe Rangel de Souza Machado ${ }^{\mathbf{1}}$ Ricardo Ventura Santos ${ }^{\mathbf{1}, \mathbf{2}}$, Carolina Arouca Gomes de Brito ${ }^{3}$

DOI: 10.1590/0103-11042019S811

RESUMO Em 23 de setembro de 1999, foi aprovada a criação do subsistema de saúde indígena no âmbito do Sistema Único de Saúde. Neste trabalho, analisamos as bases discursivas de convergência e conflitos entre discursos indigenistas e da Reforma Sanitária, que nos permitem refletir sobre esse processo que consideramos configurar uma 'longa' Reforma Sanitária indígena. Utilizamos como referencial teórico a perspectiva da teoria de Stephen Ball, para analisar documentos produzidos por atores indigenistas (Fundação Nacional do Índio - Funai, Conselho Indigenista Missionário - Cimi e União das Nações Indígenas - UNI) e pelo Movimento da Reforma Sanitária. Apontamos evidências da utilização por indígenas e indigenistas dos argumentos e das propostas da Reforma Sanitária, e, por outro lado, o envolvimento estratégico de Sergio Arouca nos debates da saúde indígena. Os pontos de convergência se localizam principalmente na crítica ao modelo biomédico, à aproximação das propostas da atenção primária e do conceito ampliado de saúde. Os conflitos se relacionaram principalmente quanto à operacionalização do subsistema, mas o discurso indigenista, contrário à municipalização, encontrou na distritalização uma proposta legitimada na Reforma Sanitária.

PALAVRAS-CHAVE Saúde de populações indígenas. Política de saúde. Reforma dos serviços de saúde.

ABSTRACT On September 23, 1999, the indigenous health subsystem was created within the scope of the Unified Health System. In this work, we analyze the discursive bases of convergence and conflicts between indigenist discourses and the health reform, which allow us to reflect on this process which we consider a 'long' indigenous health reform. We used as reference the perspective of Stephen Ball's theory, to analyze documents produced by indigenist actors (National Indian Foundation - Funai, Indian Missionary Council - Cimi and Union of Indigenous Nations - UNI) and the Health Reform Movement. We point to evidence of indigenous and indigenist use of arguments and proposals for sanitary reform and, on the other hand, the strategic involvement of Sergio Arouca in indigenous health events. The points of convergence are located mainly in the critique of the biomedical model, the approximation of primary care proposals, and the concept of health. Conflicts were mainly related to the operationalization of the subsystem, but the indigenist discourse, contrary to municipalization, found in the district process a proposal legitimized in the Health Reform.

KEYWORDS Health of indigenous people. Health policy. Heath care reform. 


\section{Introdução}

Em sua fala, na mesa de abertura da VIII Conferência Nacional de Saúde (CNS), em 1986, Sergio Arouca expressou anseios por profundas transformações na sociedade brasileira e de sua relação com o Estado. O Movimento da Reforma Sanitária enfatizava as relações intrínsecas entre saúde e democracia, mais que isso, não havia dúvidas de que não seria "possível melhorar o nível de vida da nossa população, enquanto persistisse nesse país um modelo econômico concentrador de renda e um modelo político autoritário"(41). O Golpe de 1964 favoreceu a concentração da renda e dos recursos nacionais; naquele momento, opor-se à ditadura era opor-se também às desigualdades sociais. Tal percepção também era compartilhada por representantes das nações indígenas, que, no momento de redemocratização, estavam disputando espaços e discursos da formação de políticas públicas e de poder no Estado. Disputavam, sobretudo, o direito à própria existência, na medida em que a política para os povos indígenas da ditadura ou era genocídio ou era etnocídio, com a submissão desses povos a perspectivas desenvolvimentistas e à sua 'integração' nacional.

O relatório da Comissão Nacional da Verdade evidencia que, para a ditadura, os índios eram 'suspeitos',

[...] virtuais inimigos internos, sob a alegação de serem influenciados por interesses estrangeiros ou simplesmente por seu território ter riquezas minerais, estar situado nas fronteiras ou se encontrar no caminho de algum projeto de desenvolvimento2(211).

O relatório destaca ainda a fala do Ministro Rangel Reis, em janeiro de 1976, de que "os índios não podem impedir a passagem do progresso [...] dentro de 10 a 20 anos não haverá mais índios no Brasil"2(251). Não se tratava de uma previsão acadêmica, mas de um planejamento de Estado que só viria a ser interrompido com a democratização do País, a partir de meados dos anos 1980. O mesmo relatório chama a atenção para o fato de que mais de 8 mil indígenas teriam sido mortos no período da ditadura.

Nesse cenário, o debate em torno da formulação do texto da Constituinte ganhou novas pautas. Nas palavras de Ulisses Guimarães, a Constituição de 1988 foi escrita com "ódio e nojo à ditadura"3, seus princípios representam uma oposição aos valores presentes na ditadura. Nesse sentido, foi possível inscrever na Carta Magna o art. 231 que reconhece

aos índios sua organização social, costumes, línguas, crenças e tradições, e os direitos originários sobre as terras que tradicionalmente ocupam, competindo à União demarcá-las, proteger e fazer respeitar todos os seus bens ${ }^{4}$.

Esse momento de redemocratização do País possibilitou o encontro de sujeitos com diferenças abissais na luta por valores comuns de reconhecimento, respeito e solidariedade, fundamentais para o Movimento da Reforma Sanitária e expressos na VIII CNS. Tal Conferência significou um momento de articulação de lutas anteriores e específicas que vinham acontecendo por todo o País. Para os povos indígenas, não bastava a inclusão no novo modelo de atenção nascente, mas também o exercício de uma crítica ao modelo biomédico ocidental e a defesa da necessária incorporação de suas especificidades culturais e territoriais. O modelo de descentralização municipalista, pauta fundamental da Reforma Sanitária, não lhes seria favorável. Como alternativa, foram sendo construídas experiências de implantação de distritos sanitários em territórios indígenas. A Reforma Sanitária para os indígenas, portanto, somente se materializou em 1999, com a promulgação da Lei $n^{\circ} 9.836$, que acrescenta dispositivos à Lei $\mathrm{n}^{\circ} 8.080 / 90$ e institui o Subsistema de Atenção à Saúde Indígena.

Autores $^{5-7}$ que têm se dedicado ao tema da saúde indígena no Brasil frequentemente estabelecem uma cronologia argumentativa em torno da criação do Subsistema de Saúde Indígena. Indica-se o início das discussões a 
respeito do tema na I Conferência Nacional de Proteção à Saúde do Índio (CNSPI), em 1986; em seguida, são referidas a criação da Comissão Intersetorial de Saúde Indígena (Cisi), em 1991/1992; e a realização da II Conferência Nacional de Saúde Indígena, em 1993; momentos subsequentes incluem a transitoriedade das responsabilidades legais em torno da saúde do índio entre a Fundação Nacional do Índio (Funai) e a Fundação Nacional de Saúde (Funasa), ao longo da década de 1990; culminando na aprovação da Lei Arouca, em 1999.

Essas análises, entretanto, pouco se aprofundaram na diversidade dos diferentes atores envolvidos e nos debates e disputas que ocorreram no processo. Por vezes, fica subentendido que houve um consenso na proposição da nova política de saúde indígena ao longo do período. Nossa análise neste texto procura complexificar a reflexão sobre a formulação da atual política de saúde indígena, a partir da apropriação que Rezende e Baptista ${ }^{8}$ fazem das formulações teóricas de Stephen Ball. Tal escolha analítica se deve ao fato desse autor enfatizar o caráter dinâmico e não linear da trajetória das políticas públicas. O resultado, portanto, que se delineia no presente não estaria predeterminado na origem do movimento, sendo fruto de diversas disputas: políticas, de valores, discursivas, econômicas etc.

Alternativamente às análises que compreendem o processo da política como um ciclo gradual, a perspectiva adotada por Ball se debruça em, ao menos, três sentidos: 'a política como texto', a 'política como discurso' e a 'política como processos e consequências'. Concordamos com Rezende e Baptista ${ }^{8}$ que a vantagem dessa abordagem é a possibilidade de pensar "a formação da agenda, a formulação, a implementação, e a avaliação [...] como processos integrantes"8(273) da própria política e não como etapas ou fases da política. Dessa forma, abarcamos analiticamente como os diversos grupos que disputam determinada política produzem seus discursos, como se mobilizam e como se posicionam perante ela.
Além disso, Ball8 propõe que a análise das políticas atente para, pelo menos, três contextos inter-relacionados que atuam de forma a tensionar o desenvolvimento da política. É desafio de o pesquisador elucidar os elementos constituintes e as forças específicas de cada um desses contextos. O primeiro seria o 'contexto da influência' manejado fundamentalmente por grupos de interesse no qual se constroem os discursos políticos e justificativas que dão base à política. O segundo, 'contexto de produção de textos', constitui-se dos textos legais e normativos que visam dar formalidade e oficialidade às políticas propostas. $\mathrm{O}$ terceiro contexto destacado pelo autor é o 'contexto da prática' no qual emergem os conflitos políticos e as disputas ideológicas que envolvem "a interpretação e a tradução dos textos para a realidade"8(278). Mais uma vez importa ressaltar que a política é 'texto e discurso' presente em todos os contextos mencionados.

Neste artigo, concentraremos nossa análise na proposição da política como texto, pois a política de saúde indígena foi objeto de muita disputa, tanto política quanto valorativa e discursiva identificada em uma profusão de documentos produzidos no período da Reforma Sanitária Brasileira. Essa perspectiva analítica contempla nosso objetivo na medida em que nos debruçamos sobre textos produzidos por diversos grupos que se constituíam como estratégias discursivas para mobilizar o debate e conquistar apoio social e político para a formulação de uma nova política de saúde direcionada aos povos indígenas. Tais textos permitem "uma pluralidade de leituras"8(275) que, nos embates públicos, ensejaram "acordos, interpretações e reinterpretações"8(275) pelos diversos grupos e sujeitos envolvidos no processo de construção de políticas, confluindo para a conformação do modelo de atenção à saúde indígena, composto, organizativamente, por 34 Distritos Sanitários Especiais Indígenas (DSEI). Neste estudo, evidenciaremos especificamente a identificação das convergências e conflitos entre o discurso indigenista e sanitarista sobre a reformulação da atenção à saúde 
dos povos indígenas, em eventos ocorridos na década de 1980, período da Reforma Sanitária.

Este trabalho faz parte de um esforço amplo de revisão do processo de formulação da atual política de saúde indígena desenvolvido pela pesquisa 'Saúde dos povos indígenas no Brasil: perspectivas históricas, socioculturais e políticas', que pretende, por meio de uma abordagem histórico-antropológica, investigar a trajetória dos atores e os contextos atuais das políticas de saúde voltadas para os povos indígenas. Ademais, analisaremos parte do acervo documental levantado para essa pesquisa, desde março de 2018. Esse material é constituído por acervos de instituições (governamentais e não governamentais) e pessoais de atores envolvidos no período, constituindo um conjunto inédito que ainda está em organização e análise. Ressaltamos que as principais contribuições vieram das instituições indigenistas e de doação dos atores que acompanharam todo processo; destacamos neste texto as contribuições do Conselho Indigenista Missionário (Cimi), em Brasília.

\section{O contexto histórico da emergência dos debates sobre a reformulação da política de saúde direcionada aos povos indígenas}

Pode-se dizer que o primeiro movimento de institucionalização de um discurso sobre a saúde indígena no Brasil ocorreu entre 1910 e 1967, no período de atuação do Serviço de Proteção aos Índios (SPI). Tratava-se de uma atuação que, por várias décadas, envolvia apenas ações pontuais de assistência sanitária aos indígenas, como a manutenção de alguns postos com enfermeiros, realização de convênios itinerantes de prestação de assistência médica e/ou produção de levantamentos sanitários entre os grupos indígenas9,10. Contudo, não se deve perder de vista algumas investidas institucionais no âmbito da saúde, sobretudo a estruturação do Plano de Serviço Médico do SPI, em 1947, no âmbito da Seção de Estudos do mesmo órgão, que consistia na necessidade de criar uma especialidade para a saúde indígena, reconhecendo as especificidades culturais de cada povo atendido.

Na década de 1950, as atividades empreendidas por Noel Nutels também representaram um avanço importante no atendimento sanitário de populações indígenas em áreas de difícil acesso, por meio do Serviço de Unidades Sanitárias Aéreas (Susa) vinculado ao Serviço Nacional de Tuberculose do Ministério da Saúde ${ }^{5,11,12}$.

Com o fim do SPI e com a criação da Funai em 1967, que herdou suas funções, pouco se avançou no tocante à estruturação de um 'modelo' de serviço médico ou de assistência sanitária regular às populações indígenas do País ${ }^{5,12}$. Durante a década de 1970, a Funai atuou a partir do modelo assistencial das 'Equipes Volantes de Saúde' (EVS), formato baseado no Susa, coordenadas por Noel Nutels e pelo médico José Antônio Nunes de Miranda, ambos vinculados ao Programa de Controle da Tuberculose do Ministério da Saúde ${ }^{11}$. Além disso, nesse mesmo período, a Funai ampliou a política de convênios no âmbito da prestação de serviços de saúde aos indígenas, firmados especialmente com: organizações missionárias, a Superintendência de Campanhas de Saúde Pública (Sucam), a Fundação Serviços de Saúde Pública (FSESP), a Universidade do Estado do Amazonas (UEA), Ministério da Saúde, hospitais privados, entre outros ${ }^{13}$.

Ainda no contexto da década de 1970, outras iniciativas e outros atores sociais começaram a ter um papel importante no debate em torno da construção de um modelo de assistência sanitária aos indígenas do País. Eram instituições universitárias, entidades da sociedade civil, missionários, serviços de saúde, entre outros, que desenvolveram ações de saúde em comunidades indígenas; formaram agentes indígenas de saúde; promoveram debates entre as lideranças indígenas; realizaram levantamentos 
demográficos e de saúde; encaminharam denúncias acerca de epidemias e ameaças aos povos indígenas; produziram materiais de divulgação, entre outras atividades relacionadas com a pauta indigenista mais ampla.

Além da Funai, destacaremos nesta análise outros dois outros atores ligados à sociedade civil, quais sejam: o Cimi e a União das Nações Indígenas (UNI). Ao longo dos anos 1970 e 1980, o Cimi, criado em 1972, foi uma das instituições não governamentais indigenistas que mais influenciou a pauta de direitos dos povos indígenas do Brasil, inclusive à terra ${ }^{\mathbf{1 4}}$. Desde sua criação, o Cimi está organizado em unidades regionais (Amazônia Ocidental, Sul, Nordeste, Goiás/Tocantins, Mato Grosso do Sul, Mato Grosso, Leste, Rondônia, Maranhão, Norte I e Norte II), o que permitiu uma observação ampliada sobre as condições de vida das diversas populações indígenas do País. Já no início de suas atividades, a questão da saúde esteve na pauta, sempre em diálogo com a demanda pela demarcação de terras indígenas. O Cimi atuava na área de saúde com os povos indígenas de diversas maneiras: promovendo ações de saúde em algumas comunidades indígenas, na produção de cartilhas e materiais educativos sobre saúde, na formação de agentes de saúde indígenas e realizando encontros para debater o tema. Em função da crescente atuação do órgão na área da saúde, passou a contar com uma assessoria de saúde própria e permanente a partir de 1983 . No âmbito da assessoria de saúde do Cimi, foram elaborados alguns levantamentos da situação de saúde em áreas indígenas.

Outro ator importante nesse debate foi a UNI, a primeira entidade indígena criada para reunir as lideranças das comunidades indígenas e defender seus interesses no âmbito nacional. Essa entidade emergiu do debate sobre a representação indígena nas interlocuções com sociedade civil e o Estado, procurando superar a relação tutelar e construir a autodeterminação dos povos indígenas. A UNI tem como marco para sua criação o I Seminário de Estudos Indigenistas, realizado em 1980, na cidade de Campo Grande15. Vale destacar que, durante a constituinte, suas lideranças exerceram um papel fundamental na defesa do capítulo referente aos direitos indígenas aprovado na Constituição de 1988.

Ao longo da década de 1980, esses diferentes atores indígenas e indigenistas se colocaram em um diálogo intenso sobre a situação de saúde dos povos indígenas e a atuação do órgão indigenista oficial, a Funai. Consideramos que três fatores impulsionaram esses debates: 1) uma crescente pressão dos próprios indígenas na busca de garantias de suas condições de vida e de construção de seus direitos, confluindo para a emergência da UNI; 2) constantes denúncias nos meios de comunicação acerca da ocorrência de epidemias e violências que atingiam diversos segmentos dos povos indígenas, sobretudo em decorrência dos projetos de desenvolvimento dos governos militares, que geravam repercussões e pressões internacionais; e 3) a existência de uma rede de atores indigenistas, incluindo técnicos no interior da Funai, preocupados com situação de saúde dos povos indígenas.

\section{Mudanças nos rumos dos discursos sobre saúde indígena}

Nossa pesquisa documental identificou, ao longo da década de 1980, a produção de documentos e relatórios de eventos que, tomados em conjunto, evidenciam a ocorrência de um intenso debate acerca da situação de saúde dos povos indígenas no País. Essa produção textual no período nos permite apontar um acúmulo discursivo sobre críticas e alternativas para a formulação de uma 'nova política de saúde indígena' durante a década de 1980.

Procuramos analisar os discursos que mobilizaram os atores para essa pauta nas suas interfaces com a Reforma Sanitária, tendo como marco acontecimentos que ocorreram próximos à I CNSPI, reunião temática da VIII CNS, realizada em novembro de 1986. 
A fim de elaborar uma resposta política aos problemas materiais que vinham se apresentando, a Funai organizou três eventos entre 1984 e 1985 para avaliar as ações desenvolvidas e elaborar orientações para a reorganização do modelo de atenção para os povos indígenas. Esses eventos reuniram não somente técnicos e diretores da Funai, mas também representantes de instituições de pesquisa e universitárias, organizações não governamentais, representantes de serviços de saúde, e outros que atuavam na área de saúde e instituições indigenistas; em dois deles se menciona a participação de indígenas.

O primeiro evento foi realizado em parceria com a Escola Paulista de Medicina (EPM), em 1984, intitulado Encontro sobre Problemas Indígenas na Área de Saúde. O objetivo era "promover uma discussão ampla acerca da assistência médica que é dada ao índio brasileiro"16(1). O relatório enfatiza a crítica ao modelo de assistência médica prestada aos indígenas, principalmente por sua perspectiva curativista que estaria levando "os indígenas a adquirir o hábito do consumo indiscriminado de medicamentos em detrimento de sua medicina natural”16(2). O relatório conclui:

Em resumo, uma nova política de saúde indígena deve ser desenvolvida centrada na participação ativa do grupo tribal na produção de sua saúde; no reconhecimento da eficácia dos processos terapêuticos naturais; na não apenas medicamentalização do índio; no atendimento a nível primário, secundário e terciário (uma visão sanitária antes que exclusivamente curativa); no estabelecimento de atendimentos prioritários; no recrutamento e na seleção de pessoal médico e para-médico possuidores de conhecimentos na área antropológica e na funcionalização do pronto atendimento emergencia|16(4-5).

Destacamos nesse documento a reflexão sobre as especificidades dos determinantes de saúde dos povos indígenas, da preparação dos profissionais de saúde e a preocupação sobre as condições das populações indígenas de aldeamentos na periferia das cidades.

O segundo evento é denominado Encontro sobre Saúde Indígena, ocorrido em Brasília, de 24 a 29 de janeiro de 1985. Caracteriza-se como um grupo de trabalho que convoca uma ação articulada entre diferentes instituições e comunidades indígenas diante da 'gravidade' do cenário. No relatório, depois da contextualização dos eventos trágicos pós-contato, seguem diversas proposições gerais que destacam o controle e a melhoria da qualidade da atuação já desenvolvida, com melhor vigilância epidemiológica, preparação dos profissionais e valorização da cultura tradicional e etnomedicina ${ }^{17}$. Nesse evento, é ressaltada a importância da reflexão social sobre a 'problemática indígena', e uma resolução para 'garantir a posse da terra e estimular a aplicação de técnicas agrícolas'. No final desse encontro, alerta-se:

Concluindo as discussões e observações efetuadas pelo grupo e enriquecidas por depoimentos de representantes de várias etnias, mostram que, a não serem prontamente tomadas as medidas aqui propostas e as demais que se fizerem necessárias, ocorrerá o rápido extermínio de todas as nações indígenas brasileiras ${ }^{17(3)}$.

O terceiro evento, chamado Simpósio: Alternativas sobre Saúde Indígena, ocorreu no Museu do Índio, no Rio de Janeiro, de 12 a 14 de fevereiro de 1985. Nele, já há referências ao processo da constituinte e ao debate sobre uma nova política indigenista, apontando para o 'reconhecimento de um Estado plurinacional e multiétnico'18. No texto oriundo do evento, ressalta-se que, ao se abordar o tema da saúde e doença dos povos indígenas, "não se deve restringir à simples concepção empirista e mecanicista de doença enquanto apenas uma disfunção fisiológica e orgânica" que leva a "um mero assistencialismo médico e uma medicalização do índio"18(1).

Dessa forma, defende-se a 'causação social da doença' dos povos indígenas e, daí 
decorrente, sugere-se "a elaboração de uma política de saúde para as comunidades indígenas deve partir do conceito abrangente de saúde como um bem-estar físico, social e mental”"18(1). Por isso, “[...] a elaboração de uma nova política de saúde para as comunidades indígenas implica na elaboração de uma nova política indigenista"18(5), ressaltando-se o papel da proteção dos territórios indígenas. Nesse simpósio, propôs-se que, antes de reformular uma política de saúde indígena, deveria ser feito um levantamento sistemático da questão sanitária indígena no País, apresentando-se no relatório diversos objetivos gerais e específicos para implementar essa avaliação.

Um assessor da saúde da Funai, presente nesse Simpósio, produziu um relatório complementar sobre o evento, por considerar que alguns assuntos ficaram 'muito implícitos'. Nesse documento, detalham-se diversas propostas para reorganização estrutural da atuação em saúde da Funai, sugerindo parcerias com universidades e instituições de pesquisa, pois “a Funai, por si só, não terá fôlego suficiente"19(2). Esse é um indício de que havia o questionamento da responsabilidade da Funai na assistência à saúde dos povos indígenas. Ademais, indica que são essas outras instituições em que se encontra "a medicina 'preventiva”" [grifo nosso] ${ }^{19(4)}$.

Esse documento complementar destaca ainda uma reflexão sobre o modelo de atenção naquele momento:

[...] foi analisado ação da EVS (Equipe Móvel de Saúde) da FUNAl, e se concluiu de que a mesma, na maioria das Regionais, o seu custo tem sido elevado, com baixíssimo benefício para a promoção da saúde. A solução para se tornar eficaz as 'ações básicas de saúde', às populações indígenas, não é a EVS o elemento primordial, e sim os paramédicos, bem capacitados, e dando ênfase ao próprio índio paramédico, pois, é este que vai morar definitivamente no loca|19(6).

A análise conjunta desses documentos derivados dos eventos evidencia que havia um conjunto significativo de atores envolvidos com a atuação na saúde dos povos indígenas, que eram acionados pela Funai em seus eventos. No entanto, prevalece nos textos a crítica ao modelo de saúde executado pela Funai, especialmente pelo seu caráter curativista e medicalizante, e, consequentemente, apontava-se para a necessidade de construção de um novo modelo de atenção para a saúde indígena. Muitas sinalizações desses debates parecem apontar para diretrizes indicadas pela Conferência de Alma-Ata e pela Reforma Sanitária Brasileira, como a ênfase na atenção primária, a utilização dos recursos locais e maior participação comunitária.

Podemos dizer, portanto, que tanto as questões quanto as soluções propostas no âmbito dos debates da saúde indígena dialogaram diretamente com pontos estratégicos da Reforma Sanitária. Tal diálogo nos indica que havia uma circulação dos atores indigenistas nos espaços da Reforma Sanitária, com compartilhamento de ideias, valores e referenciais teóricos.

Essa articulação com o Movimento da Reforma Sanitária expressou-se também na participação ativa de indigenistas e indígenas na VIII CNS, que, nesse momento, articularam com as lideranças da Reforma Sanitária a organização de uma conferência temática sobre saúde indígena. Assim, entre 26 e 29 de novembro de 1986, ocorreu a I CNPSI, em Brasília, que foi organizada pela Secretaria de Programas Especiais do Ministério da Saúde e contou com a participação de Sergio Arouca, presidente da VIII CNS, na mesa de abertura. Essa conferência teve como objetivo discutir as bases para uma nova política de saúde indígena que contemplasse as especificidades desses povos e ampliasse a participação indígena.

Para essa conferência, foi solicitado aos diversos atores indigenistas ligados à saúde que apresentassem propostas para a formulação da nova política de saúde. A edição especial 'Saúde do Índio' da revista 'Saúde em Debate' (jan. 1988) reuniu os textos elaborados para os debates da I CNPSI. Os dois textos iniciais dessa revista, de autoria da UNI e do Cimi, segundo o 
editorial da revista, procuram destacar a voz das entidades indígena e indigenista sobre a política de saúde direcionada aos povos indígenas.

$O$ texto da UNI se inicia com uma contextualização da questão indígena, da sua diversidade e do histórico das relações de contato e com o Estado, de modo que se afirmam alguns pontos que coincidem com suas reivindicações no processo constituinte:

O direito à saúde passa necessariamente pelo reconhecimento da cidadania plena dos povos indígenas e por medidas que assegurem: a posse de suas terras; o respeito à sua organização político-cultural; o acesso às ações e serviços de promoção, proteção e recuperação da saúde 20(8).

Pontua-se que "é dever do Estado assegurar efetivamente"20(8) esses direitos. Dadas as especificidades dos povos indígenas, propõe-se a criação de uma secretaria vinculada ao Ministério da Saúde, mantendo a participação das lideranças indígenas na organização, planejamento e gestão das ações de saúde. Como princípios para a organização dos serviços, são destacados: a participação das populações indígenas; o respeito às práticas tradicionais em saúde das populações indígenas; a importância da educação em saúde; a ênfase na Atenção Primária à Saúde (APS); a incorporação dos agentes indígenas na atenção à saúde; e o "estímulo à formação de pessoal em saúde, nas próprias comunidades indígenas"20(9).

O documento do Cimi destaca a posse da terra como "elemento primário e essencial para se atingir qualquer respeito à condição dessas comunidades, como povos que são"21(10), reforçando o discurso empreendido pelo órgão desde a década de 1970. O texto segue apresentando um breve panorama da situação de saúde das populações indígenas do País no período e responsabilizando o Estado pelas falhas na prestação da assistência aos índios.

A última parte apresenta seis propostas de 'reformulação do Sistema Nacional de Saúde', como a necessidade de garantia e integridade das terras indígenas; o respeito à identidade étnico-cultural e medicina nativa; a responsabilidade do Estado com participação ativa dos povos indígenas; e a criação de uma Secretaria Técnica Federal Indígena, que deveria estar vinculada ao Conselho Nacional de Saúde ${ }^{21}$.

Em linhas gerais, o relatório final da I Conferência ${ }^{22}$ contempla as proposições da UNI e do Cimi em torno da formulação de um novo modelo de atenção à saúde indígena, em relação à proposta da criação de uma agência/ secretaria de saúde indígena ligada diretamente ao Ministério da Saúde, à centralidade da questão da terra, do respeito às especificidades socioculturais dos povos indígenas e à maior participação indígena.

A edição especial 'Saúde do Índio' da revista 'Saúde em Debate' (jan. 1988) evidencia a falta de proposições da Funai nos debates da I CNPSI para a nova política de saúde indígena. Os discursos sobre a construção de uma nova política de saúde direcionada aos povos indígenas geraram paralelamente um debate sobre a mudança no modelo institucional da política indigenista da saúde. Os documentos do Cimi e da UNI apontam diversas críticas à atuação do órgão indigenista. Em decorrência disso, no início da década de 1990, ocorreu uma clara disputa e tensionamento no campo da saúde indígena, em um embate entre Ministério da Saúde e Funai pela responsabilidade pela execução das ações de saúde direcionadas aos povos indígenas ${ }^{5}$.

Esse conjunto de textos produzidos ao longo da década de 1980, tanto resultantes dos eventos organizados pela Funai quanto as contribuições para a I CNPSI publicadas na revista 'Saúde em Debate', evidencia que diversos atores vinham produzindo análises e proposições acerca das ações de saúde direcionadas aos povos indígenas. Esse acúmulo irá fundamentar os debates e as formulações da nova política de saúde indígena no âmbito da Reforma Sanitária Brasileira, sendo que nos interessa analisar suas convergências e divergências. 


\section{Os diálogos entre discursos indigenistas e a Reforma Sanitária}

Observamos que os discursos produzidos no âmbito dos debates indigenistas anteriores a I CNPSI dialogam com os debates da Reforma Sanitária sobre a crítica ao modelo de atenção então vigente. Os documentos produzidos para essa mesma conferência apontam para uma proposição de um novo modelo alinhado aos princípios construídos na VIII CNS. Ambos os setores, indigenistas e sanitaristas, deslocaram "a ênfase da questão da saúde-doença para a determinação social desses processos e práticas de saúde"23(17). A convergência dos diagnósticos apontava para a necessidade de superação da forma de condução das políticas públicas marcadas fundamentalmente por valores autoritários, medicalizantes, privatistas, iatrogênicos e ineficientes. Esse diálogo acontecia em função da participação dos atores indígenas e indigenistas nos espaços de debate da Reforma Sanitária, e uma solidariedade e sensibilidade dos sanitaristas para as pautas indígenas.

O relatório da I CNPSI evidencia as aproximações do discurso indigenista com os valores e diretrizes da Reforma Sanitária. Destacase, nesse sentido, a referência aos marcos da APS a partir da compreensão da "saúde como um completo bem-estar físico, mental e social"22(60); a participação dos indígenas no processo de formulação e execução da política de saúde; a proposição da organização dos serviços a partir do nível local baseado na estratégia da APS; e a articulação com os demais níveis do sistema nacional. O conceito ampliado de saúde é uma abertura importante para inclusão das especificidades indígenas no âmbito da saúde, pois

a saúde indígena das nações indígenas é determinada num espaço e tempo histórico e na particularidade do seu contato com a sociedade nacional, pela forma de ocupação do seu

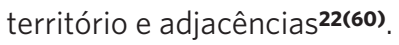

Vemos nesse documento que, no contexto da discussão da nova política de saúde indígena, havia convergências entre as perspectivas da Reforma Sanitária e da 'nova política indigenista'. O discurso de Arouca, na mesa de abertura da I CNPSI, foi emblemático desse diálogo e aproximações. Em sua fala, Arouca retomou alguns dos argumentos centrais presentes no discurso da VIII CNS, reafirmando a necessária vinculação entre avanços sociais e democratização do País. Se na abertura da VIII CNS Arouca reforçou que o ponto de partida para a melhoria das condições de saúde da população seria a superação do 'modelo econômico concentrador de renda e um modelo político autoritário', na I CNPSI, ele ressaltou que "a política de saúde no país começa na política econômica e na política social, que são resultantes da política de afirmação de um povo"24(1-2). Avança no sentido específico da questão indígena afirmando que "a questão da cidadania envolve o respeito à história e à cultura de cada grupo dentro de nossa sociedade"24(2) e que "na democracia que queremos é fundamental tratar de questões como a dos índios com toda a dimensão social, técnica e científica"24(2). Arouca insistia na tríade democracia/política social/política econômica como única forma possível de se avançar na construção do País; não obstante, temas como reforma agrária e demarcação de terras indígenas fizeram parte do léxico político desse momento histórico.

Na edição especial 'Saúde do Índio' do Centro Brasileiro de Estudos de Saúde (Cebes), de 1988, existe um texto de autoria de Armando Negri Filho que procura apontar os caminhos para a operacionalização de um novo sistema de saúde indígena, e diz:

a Reforma Sanitária prevê a divisão do país em Distritos Sanitários regionais. Como poderiam ser estabelecidos esses distritos em regiões habitadas por populações indígenas?25(19).

Naquele momento, a Comissão Nacional da Reforma Sanitária apresentava o "distrito 
sanitário como unidade operacional básica do Sistema Nacional de Saúde"26(18). É interessante notar que a distritalização vai se manter como a proposição organizativa do subsistema, mas não do SUS, que adota a municipalização.

Em 1989, foi realizado em Brasília o VI Simpósio sobre Política Nacional de Saúde para debater a construção da Lei Orgânica do Sistema Único de Saúde (SUS), no qual foi incluído o tema 'Sistema de Saúde Indígena' com a seguinte consideração:

Propõe-se: que seja especificada na lei orgânica do Sistema Único de Saúde: o direito dos grupos indígenas a uma atenção integral à saúde, diferenciada em função dos vários aspectos, que determinam ou acondicionam sua situação sanitária, bem como o reconhecimento e garantia de organização e de sistemas de saúde próprios de cada grupo 27(189-190).

No entanto, tal especificação não ocorreu na primeira versão aprovada da Lei ${ }^{\circ} 8.080 / 90$, e, por isso, foi enviado um projeto de lei, em julho de 1994, pelo então deputado Sergio Arouca, propondo a criação do Subsistema de Saúde Indígena no SUS. Essa lei só foi sancionada em definitivo em setembro de 1999, ficando conhecida como Lei Arouca (Lei no 9.836/99).

É importante, no entanto, marcar uma diferença entre as propostas do movimento sanitarista e os indígenas e indigenistas no que diz respeito à condução das políticas de saúde. Uma vez que os sanitaristas defendiam a municipalização na implantação do SUS, essa não era a alternativa aventada para a condução da saúde indígena, pelo movimento indígena e indigenistas. A responsabilidade pelas questões indígenas constitui-se historicamente como jurisdição federal devido aos conflitos de interesse, principalmente por terras, com poderes locais e regionais. No contexto dos debates constituintes dos direitos indígenas, mantém-se a defesa da competência da União para as políticas indigenistas. Os documentos do Cimi e da UNI apontavam que a nova política de saúde indígena deveria ser gerida diretamente pelo
Ministério da Saúde, demanda que será somente conquistada em 2010, com a criação da Secretaria Especial de Saúde Indígena (Sesai).

A IX CNS, em 1992, apontava a municipalização como caminho técnico-político para implantação do SUS, descentralizando a execução das ações e fortalecendo a participação política ${ }^{28}$. Entretanto, historicamente, o movimento indígena e indigenista foi contrário à municipalização por questões de conflitos locais por terra, entre outros. Dessa forma, um grupo de lideranças indígenas e indigenistas marca presença na IX CNS e aprova em seu relatório final a proposta de que:

É necessário garantir no SUS ação integral à saúde dos povos indígenas de forma diferenciada, em função das especificidades étnico-culturais e da situação [incompreensível] com garantia de seus sistemas tradicionais de saúde, por meio da criação de distritos sanitários especiais indígenas, diretamente ligados ao Ministério da Saúde e administrados por Conselhos Indígenas de Saúde ${ }^{29(28) .}$

No entanto, mesmo a alternativa 'discordante' dos indígenas e indigenistas encontra respaldos na Reforma Sanitária. A distritalização é uma estratégia de reorganização dos serviços de saúde que surgiu no Brasil no final da década 1980, por influência dos debates internacionais sobre Sistemas Locais de Saúde (Silos), desenvolvidos pela Organização Pan-Americana da Saúde (Opas) ${ }^{28}$. Tal proposta ganhou acolhida no Brasil em função das aproximações com os valores do Movimento da Reforma Sanitária, que preconizava regionalização das ações, maior participação dos atores locais, uma concepção ampliada de saúde e a reorganização das práticas de saúde ${ }^{28}$.

Essa proposição tem como conceito-chave a dimensão territorial entendida como processo social ${ }^{28}$, que transcende a delimitação física e, dessa forma, dialoga com a pauta indígena de defesa dos territórios indígenas, e na sua concepção de terra como relações sociais, culturais e de memória. Dessa forma, a distritalização serviu de contraproposta à municipalização, pois 
era um modelo que respeitava os territórios indígenas, cujos limites e características não se definem por divisões administrativas de municípios ou estados, e fortalecia a manutenção da responsabilidade da União na execução das ações de saúde.

\section{Considerações finais}

A criação do SUS foi a maior conquista do Movimento da Reforma Sanitária. Mesmo tendo tido importantes derrotas, como a questão do financiamento, os valores presentes no SUS impuseram a necessidade de estruturação de um novo modelo de atenção baseado nos princípios/valores de universalidade, igualdade, integralidade e participação da sociedade. Tais princípios embasaram igualmente a concepção da política de saúde indígena que vinha sendo discutida, como destacamos por meio da análise dos documentos do Cimi e da UNI e, principalmente, no relatório final da I CNPSI.

A leitura de tais documentos nos permite apontar um acúmulo, ao longo da década de 1980, de uma intensa produção discursiva, por diversos atores, sobre a saúde indígena e com suficientes confluências com o movimento sanitarista para justificar a criação e a inclusão do subsistema de saúde indígena na lei orgânica do SUS. Destacamos as consonâncias com a concepção ampliada da saúde, organização a partir da atenção primária, o fortalecimento da participação social e a distritalização. As concepções presentes na política de saúde indígena, expressas na Lei ${ }^{\circ} 9.836 / 99$, produto dos debates entre diferentes atores, estão em consonância com os termos da Reforma Sanitária e do SUS. A participação ativa de indígenas e indigenistas nos eventos da Reforma Sanitária, como a VIII e a IX CNS, e, por outro lado, o envolvimento estratégico de Sergio Arouca nos debates da saúde indígena, na mesa de abertura da I CNPSI e apresentando a lei para criação do subsistema como deputado federal, foram fundamentais na consecução do atual modelo de atenção à saúde indígena.
Apesar das distâncias abissais que separavam as realidades materiais e simbólicas de indígenas e não indígenas, os atores do Movimento da Reforma Sanitária (com destaque para a atuação de Sergio Arouca) foram capazes de se sensibilizar e incorporar as demandas do movimento indígena e indigenista sobre as especificidades dos povos indígenas na sua inclusão no sistema nacional de saúde. Todo esse processo conformou o que estamos chamando de 'longa' Reforma Sanitária indígena.

No entanto, os diferentes interesses e perspectivas sobre os direitos dos povos indígenas e as políticas de saúde continuam em debate e disputa, dessa forma, seria ingênuo aceitar que essa longa reforma teria terminado. No atual contexto, os povos indígenas têm seus direitos constitucionais ameaçados, seus territórios invadidos e as políticas públicas específicas revisadas. Assim, desconsiderando toda a trajetória de construção da saúde indígena no SUS, no início de 2019, o Ministério da Saúde propôs a extinção da Sesai e a municipalização de parte do subsistema, com o argumento de que este seria 'paralelo ao SUS ${ }^{30}$. Esse processo foi revertido pela atuação política do movimento indígena, mas a VI Conferência Nacional de Saúde Indígena foi adiada, e as instâncias do controle social indígena estão fragilizadas.

É fundamental, neste momento, mantermo-nos atentos ao processo de (des)construção da política de saúde para os povos indígenas. A mobilização vista nas décadas anteriores logrou importantes vitórias para a construção de nossa sociedade, que inclui a defesa dos direitos dos povos indígenas. Resta-nos apostar que seremos capazes de reviver aquele espírito solidário e democrático para não apenas mantermos as conquistas passadas, mas sermos capazes de exigir mais.

\section{Colaboradores}

Pontes ALM (0000-0001-9162-5345)* contribuiu para a concepção e planejamento da 
pesquisa, análise e interpretação dos dados; para a elaboração do rascunho e revisão crítica; e aprovação da versão final do manuscrito. Machado FRS (0000-0002-5028-8888)* contribuiu para a análise e interpretação dos dados; elaboração do rascunho e aprovação da versão final do manuscrito. Santos RV (00000001-5071-443X)* contribuiu para a concepção e planejamento da pesquisa, análise e a interpretação dos dados e aprovação da versão final do manuscrito. Brito CAG (0000-0003-29783072)* contribuiu para concepção, análise e interpretação dos dados; revisão crítica do conteúdo; e participação na versão final do manuscrito.

\section{Referências}

1. Brasil. Ministério da Saúde. Anais da $8^{\text {a }}$ Conferência Nacional de Saúde. Brasília, DF; 1987. 430 p. [acesso em 2019 out 7]. Disponível em: http://www.ccs.saude.gov.br/cns/pdfs/8conferencia/8conf_nac_anais. pdf.

2. Comissão Nacional da Verdade. Violações de direitos humanos de povos indígenas. [acesso em 2019 out 1]. Disponível em: http://cnv.memoriasreveladas.gov.br/images/pdf/relatorio/Volume\%202\%20-\%20Texto\%205.pdf.

Brasil. Câmara dos Deputados. Discurso proferido na sessão de 5 de outubro de 1988, publicado no DANC de 5 de outubro de 1988 [internet]. [acesso em 2019 out 7]. Disponível em: https://www2.camara.leg.br/ atividade-legislativa/plenario/discursos/escrevendo historia/25-anos-da-constituicao-de-1988/cons-
tituinte-1987-1988/pdf/Ulysses\%20 Guimaraes\%20-

-\%20DISCURSO\%20\%20REVISADO.pdf.

4. Brasil. Constituição, 1988. Constituição da República Federativa do Brasil. Brasília, DF: Senado Federal; 1988. [acesso em 2020 fev 16]. Disponível em: https://www.senado.leg.br/atividade/const/con1988/ con1988_26.06.2019/art_231_.asp.

5. Cardoso AM, Santos RV, Garnelo L, et al. Políticas públicas de Saúde para os povos indígenas. In: Giovanella L, Escorel S, Lobato LVC, et al., organizadoras. Políticas e sistema de saúde no Brasil. Rio de Janeiro: Fiocruz, 2012. p. 911-932.

6. Garnelo L, Macedo G, Brandão LC. Os povos indígenas e a construção das políticas públicas no Brasil. Brasília, DF: OPAS; 2003.
*Orcid (Open Researcher and Contributor ID). 
7. Garnelo L. O SUS e a saúde indígena: matrizes políticas e institucionais do Subsistema de Saúde Indígena. In: Teixeira CC, Garnelo L, organizadoras. Saúde indígena em perspectiva: explorando suas matrizes históricas e ideológicas. Rio de Janeiro: Fiocruz, 2014. p. 107-142.

8. Rezende M, Baptista TWF. A análise da política proposta por Ball. In: Mattos RA, Baptista TWF, organizadores. Caminhos para análise das políticas de saúde. Porto Alegre: Rede UNIDA, 2015. p. 273-283.

9. Brito CAG, Lima N T. Antropologia e Medicina: a saúde no Serviço de Proteção aos Índios (1942-1956). In: Teixeira CC, Garnelo L, organizadoras. Saúde indígena em perspectiva: explorando suas matrizes históricas e ideológicas. Rio de Janeiro: Fiocruz, 2014. p. 59-84.

10. Brito CAG. Medicina e antropologia: atenção à saúde no Serviço de Proteção aos Índios (1942-1956). 2011. [dissertação]. Rio de Janeiro: Fundação Oswaldo Cruz, 2011. 115 p.

11. Paz MC. Noel Nutels: a política indigenista e a assistência à saúde no Brasil Central (1943-1973). [dissertação]. Rio de Janeiro: Instituto de Medicina Social, Universidade do Estado do Rio de Janeiro, 1994.

12. Costa DC. Política Indigenista e assistência à saúde Noel Nutels e o Serviço de Unidades Sanitárias Aéreas. Cad. Saúde Pública.1987; 4(3):338-401.

13. Selau MG. A política indigenista governamental: aspectos ideológicos e administrativos da ação médico-sanitária entre as populações indígenas brasileiras (1967 a 1988). Relatório de Pesquisa. Brasília, DF: FUNAI; 1992.

14. Teixeira MCS. Igreja Católica e ação indigenista na Amazônia contemporânea: o CIMI (1972-2000) [dissertação]. Manaus: Universidade Federal do Amazonas, 2008. 135 p.

15. Deparis SR. União das Nações Indígenas (UNI): contribuição o movimento indígena no Brasil (1980-1988). [dissertação]. Dourados: Universidade Federal da Grande Dourados, 2007. 126 p.

16. Fundação Nacional do Índio; Escola Paulista de Medicina. Relatório sobre Encontro sobre problemas indígenas na área de saúde. Brasília, DF: FUNAI; 1984.

17. Fundação Nacional do Índio. Relatório do Encontro de Saúde Indígena. Brasília, DF: FUNAI; 1985.

18. Fundação Nacional do Índio. Relatório do Simpósio: Alternativas sobre saúde indígena. Rio de Janeiro: FUNAI; 1985.

19. Cunha OCD. Memo no 06/DAI. De Assessor de Saúde - DAI ao Sr. Diretor da DAI. Em 04 de fevereiro de 1985. Brasília, DF: FUNAI; 1985.

20. União das Nações Indígenas. Os povos Indígenas e o direito à Saúde. Saúde debate. 1988; (esp):8-9.

21. Conselho Indigenista Missionário. Saúde: especificidades do direito dos povos indígenas no contexto das conclusões da $8^{\mathrm{a}}$. Conferência Nacional de Saúde. Saúde debate. 1988; (esp):10-11.

22. Brasil. Encontro aponta soluções para a proteção da saúde do índio. Saúde debate. 1988; (esp):60.

23. Fleury S. Reforma Sanitária: múltiplas leituras, diálogos e controvérsias. In: Fleury S, organizadora. Teoria da Reforma Sanitária: Diálogos Críticos. Rio de Janeiro: Fiocruz, 2018. p. 15-30.

24. Arouca S. Discurso de Sergio Arouca. Presidente da $8^{a}$. Conferência Nacional de Saúde (do Índio). Brasília, DF: MS; 1986. (mimeo).

25. Negri Filho A. A saúde dos povos indígenas - a questão do sistema de saúde - propostas operacionais. Saúde debate. 1988; (esp):19-20.

26. Comissão Nacional da Reforma Sanitária. Documentos III. Rio de Janeiro: ENSP; 1987.

27. Brasil. Câmara dos Deputados. Comissão de Saúde, 
Previdência e Assistência Social. Anais do $6^{\circ}$ Simpósio sobre política nacional de saúde: Sistema Único de Saúde. Brasília, DF: Câmara dos Deputados; 1989.

28. Mendes EV. O processo social de distritalização da saúde. In: Distrito Sanitário: O processo social de mudança das práticas sanitárias do Sistema Único de Saúde. São Paulo-Rio de Janeiro: Hucitec: Abrasco; 1999. p. 93-158.

29. Brasília. Relatório Final. $9^{a}$. Conferência Nacional de Saúde. Brasília, DF, 1993. [acesso em 2020 fev 16]. Disponível em: http://bvsms.saude.gov.br/bvs/publicacoes/9_conferencia_nacional_saude_relatorio_final. pdf.
30. Folha de São Paulo [internet]. Governo federal avalia repassar saúde indígena a estados e municípios. [acesso em 2019 jun 1]. Disponível em: https://wwwl. folha.uol.com.br/cotidiano/2019/02/governo-federal-avalia-repassar-saude-indigena-a-estados-e-municipios.shtml.

Recebido em 02/06/2019

Aprovado em 04/09/2019

Conflito de interesses: inexistente

Suporte financeiro: pesquisa financiada pelo Wellcome Trust ( $n$ o 203486/Z/16/Z) 